\title{
6 Dealing with Assignments
}

Apart from the Activities which you complete as you work through the Workbooks you will find two other types of assignment associated with your course. These are:

\section{the Self Check Exercises \\ the Tutor Review Exercises}

Details of these are included in the appropriate Study Guide and each of them is likely to involve you in a little more work than the Activities which form part of the Workbook.

You will not be asked to write essays. Rather, things have been designed for you to do which form an integral part of the learning for the Unit. The Tutor Review Exercises in particular will open up communication with your tutor and will help him or her to monitor your progress and to offer help specifically designed with you in mind.

Because of the range of tasks involved in the Self Check Exercises and Tutor Review Exercises there is no detailed advice included here about how to tackle them. You will find this in the Element Study Guides.

One tip though, which you might find useful. The important thing about activities, exercises and assignments is to start them! In connection with work of this kind procrastination really is the thief of time. When you come to the point of no return don't falter. Sit down and start writing. You will almost certainly find that the first couple of sentences are the most difficult.

\section{How You Will Be Assessed}

Before your learning centre can recommend you for the award of a BTEC Certificate of Achievement to show that you have successfully completed the Unit, your tutors will naturally have to satisfy themselves that you have an adequate grasp of the ideas and skills covered in the Unit.

This information will be extracted from a variety of the exercises, assignments and project work you undertake. The exact details of how this will be done will be provided by your college at the beginning of the course and will be shown in detail on your Study Plan.

A word of reassurance is appropriate here. The Open BTEC materials have been designed to provide the maximum opportunity for students to succeed in their studies. They aren't out to 'trip you up'. If you follow the course carefully and undertake the tasks included with care then you should have no trouble in achieving success. 